\title{
Constraints of Pore-Bulk Strain Ratio and Interference Time on the Evolution of Coal Permeability during $\mathrm{CO}_{2}$ Injection
}

\author{
Guannan Liu $\mathbb{D},{ }^{1,2,3}$ Jishan Liu $\mathbb{D},{ }^{4}$ and Feng Gao $\mathbb{D}^{1,2}$ \\ ${ }^{1}$ State Key Laboratory for Geomechanics and Deep Underground Engineering, China University of Mining and Technology, Xuzhou, \\ Jiangsu 221116, China \\ ${ }^{2}$ Laboratory of Mine Cooling and Coal-heat Integrated Exploitation, China University of Mining and Technology, \\ Xuzhou 221116, China \\ ${ }^{3}$ Beijing Key Laboratory for Precise Mining of Intergrown Energy and Resources, China University of Mining and Technology, \\ Beijing 100083, China \\ ${ }^{4}$ School of Engineering, The University of Western Australia, WA 6009, Australia
}

Correspondence should be addressed to Guannan Liu; guannanliu@cumt.edu.cn

Received 6 December 2020; Revised 20 February 2021; Accepted 5 March 2021; Published 16 March 2021

Academic Editor: Guanglei Zhang

Copyright (c) 2021 Guannan Liu et al. This is an open access article distributed under the Creative Commons Attribution License, which permits unrestricted use, distribution, and reproduction in any medium, provided the original work is properly cited.

$\mathrm{CO}_{2}$ injection into coal seam triggers a series of processes that are coupled all together through a permeability model. Previous studies have shown that current permeability models cannot explain experimental data as reported in the literature. This knowledge gap defines the goal of this study. We hypothesize that this failure originates from the assumption that the pore strain is the same as the bulk strain in order to satisfy the Betti-Maxwell reciprocal theorem. This assumption is valid only for the initial state without gas sorption and deformation and for the ultimate state with uniform gas sorption and uniform deformation within the REV (representative elementary volume). In this study, we introduce the pore-bulk strain ratio and interference time to characterize the process of gas sorption and its associated nonuniform deformation from the initial state to the ultimate state. This leads to a new nonequilibrium permeability model. We use the model to fully couple the coal deformation and gas flow. This new coupled model captures the impact of coal local transient behaviors on gas flow. Results of this study clearly show that coal permeability is constrained by the magnitudes of initial and ultimate pore-bulk strain ratios and interference time, that current permeability data in the literature are within these bounds, and that the evolutions of coal permeability all experience similar stages from the initial value to the ultimate one.

\section{Introduction}

$\mathrm{CO}_{2}$ is the main contributor to the greenhouse effect. $\mathrm{CO}_{2}$ sequestration in deep nonexploitable coal seams can simultaneously reduce $\mathrm{CO}_{2}$ emissions and enhance coalbed methane recovery $\left(\mathrm{CO}_{2}\right.$-ECBM), which has great potential for development [1-4]. The study of coal permeability evolution is the main problem to enhance gas recovery of reservoir [57]. When the gas pressure drops to the desorption point, the adsorbed gas enters into pores, the matrix shrinks, and the pores' volume increases [8-10]. In the process of gas injection, solid-gas coupling leads to significant differences in permeability, and its evolution process is highly complex.
In the past few decades, several coupling models have been proposed to interpret the permeability change during $\mathrm{CO}_{2}$ injection. Based on the Langmuir model, a finite element model was proposed to investigate the coupling of sorption-induced deformation and coal seam gas flow process [11]. A multiphase flow model for the gas injection process considering the coupling of matrix deformation and heat conduction process was proposed [12]. Then, the single-porosity elastic model to study the evolution process of porosity and permeability of $\mathrm{CO}_{2}$ gas injection under in situ stress, taking into account the deformation and flow process of micropore and fracture, was revised [13, 14]. A dual porosity model considering the statistical properties of 
geological parameters, which can introduce relatively large errors, was proposed [15]. The effects of directional compaction, single fracture, and anisotropic expansion on coalbed methane reservoirs through a dual porosity model were discussed [16]. Based on the multiple porosity model, the relationship between matrix strain and macro permeability of coal by introducing the strain splitting function was studied [17]. Two nonequilibrium models with two different nonlinear adsorption isotherms, i.e. nonlinear Freundlich and Langmuir adsorption isotherms, were developed [18]. The change of fracture porosity and permeability caused by coal matrix shrinkage into the dual pore model to study the quasisteady flow in unconventional reservoirs was introduced $[19,20]$. Although these models have been used to interpret and match some experimental data, the interaction between coal matrix and fracture induced by the adsorption-induced strain has not been understood well.

Previous model conclusions $[15,21]$ are inconsistent with experimental data of huge changes in coal permeability caused by coal swelling. The experimental data are sensitive to the change of stress and pore pressure, especially for low permeability coal seams. Using transient pulse attenuation technology, it is found that the compressibility of face cleats is considerably sensitive to the sorption-induced swelling/shrinkage and offers significant effects on the coal permeability [22]. The adsorption and desorption energy of CO2 gas significantly affects the volume change of microscopic and macroscopic pores in coal, resulting in the expansion/contraction and permeability fluctuation of coal [23].Previous models usually only studied the ultimate equilibrium permeability, but neglected its evolution process. Studies [14, 22, 23 ] show that for low permeability coal seams, it often takes a long time for permeability to evolve to the final equilibrium state during gas injection. To solve this problem, a series of research was conducted [24-26] to study the change process of the intermediate nonequilibrium state in the process of coalbed methane exploitation. In recent years, a new functional relationship between coal permeability and fracture aperture was defined [27], and the evolution process of coal permeability from the initial equilibrium state to final equilibrium state was analyzed. However, the study on the division of fracture and matrix-induced strain by adsorption usually adopts the method of single or discrete fracture explicitly embedded into the models.

In this study, the explicit approach as adopted in previous studies is transformed into a continuous approach. The explicit method uses geometric methods to characterize the fracture pore structure, such as digital core method and fracture discrete network method. However, due to its high computational requirements, the analysis of large-scale multifield coupling problems is still limited $[5,6]$. In the process of gas adsorption, coal will undergo uneven deformation, which will lead to the change of throat and channel length in the internal pores; so, the pore-bulk strain ratio is introduced to characterize this change process. Under the coupling effect of stress, the change of pore pressure in coal will lead to the change of permeability. The pore volume strain ratio and interference time proposed in this work can quantitatively characterize the gas adsorption process and the accompanying nonuniform evolution process from the initial state to the final state. Thus, a new multifield coupling model of nonequilibrium permeability including fracture pore dual scale is established. Compared with the previous models, this new coupling model captures the influence of local transient behavior of coal on gas flow from the perspective of interference time. The results of this study are reported in the following sections.

\section{Governing Equations}

Coal seam is a typical dual porosity medium under the action of in situ stress [28-31]. The deformation caused by the adsorption process is one of the main inducements of coal seam permeability. Firstly, considering the pore adsorption strain ratio, a dual porosity model is established and coupled to the solid deformation equation under the influence of effective stress. The following assumptions are made for coal deformation and gas seepage process:

(1) The deformation process of coal meets linear elasticity

(2) The effect of anisotropy is not considered

(3) Gas viscosity coefficient is a constant

(4) Gas in the pores is saturated

2.1. Permeability Model. The ratio of pore strain and bulk strain induced by adsorption can be expressed as [32]:

$$
\varepsilon_{\mathrm{sp}}=\psi\left(\varepsilon_{\mathrm{sb}}\right)
$$

where $\varepsilon_{\mathrm{sp}}$ is the pore strain induced by sorption, $\varepsilon_{\mathrm{sb}}$ is the bulk strain of coal induced by sorption, and $\psi$ is the function of $\varepsilon_{\mathrm{sb}}$. According to Taylor expansion, Eq.(1) can be expressed as

$$
\varepsilon_{\mathrm{sp}}=\gamma \varepsilon_{\mathrm{sb}}
$$

where $\gamma=\partial \psi /\left.\partial \varepsilon_{\mathrm{sb}}\right|_{\varepsilon_{\mathrm{sb}}=0}$. Experimental results [15] show that the sorption-induced strain of pore is larger than that of bulk, and the two strains can be regarded as equal only when they are in the equilibrium state.

At the beginning of gas injection, the pressure in fracture is greater than that in matrix. So, gas permeates into the matrix, and the amount of adsorbed gas in the matrix increases. Then, the volume expands, and the fracture volume decreases as shown in Figure 1. We can draw the conclusion that the sign of the fracture strain is opposite to that of the matrix strain. In addition, coal porosity is usually very small $(0.001<\phi<0.03)$; so, the sorption-induced strain of matrix is approximately equal to that of bulk. Then, the sigh of the sorption-induced fracture strain is opposite to that of bulk, i.e., at the initial state $\gamma_{0}<0$. The initial value of $\gamma$ can be expressed as [33]:

$$
\gamma_{0}=\frac{C_{f} E}{3(v-1)},
$$



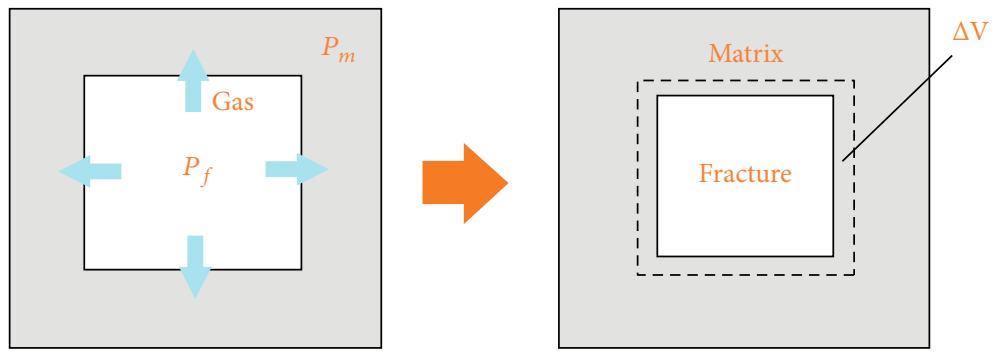

FIgURE 1: Block volume evolution induced by gas transfer between fracture and matrix.

where $C_{f}$ is the coal compressibility, $E$ is the Young's modulus of coal, and $v$ is the Poisson ratio of coal.

The characteristic interference time $\tau_{1}$ is determined by the onset of pressure interference between two hydro fractures spaced $2 d$ (as shown in Figure 2) apart and defined by [34]:

$$
\tau_{1}=\frac{d^{2}}{\lambda_{i}}
$$

$\lambda_{i}$ is the hydraulic diffusivity of gas under the initial reservoir pressure and temperature $\left(p_{i}, T\right)$, which can be measured by experiment. Pore structure, temperature, pressure, and gas composition have an important influence on the hydraulic diffusion coefficient, but here we ignore the change of temperature and pressure, assuming that the gas is an ideal gas, and considering the homogeneous reservoir; so, the hydraulic diffusion coefficient $\lambda_{i}$ is considered to be a constant.

When coal reaches the final equilibrium state, the strain ratio $\gamma=1$, which means pore strain induced by sorption, is equal to the bulk strain. In combination with equation (3), we assume that the adsorption strain ratio changes linearly from the initial state to the final equilibrium state. As shown in Figure 3, $\gamma$ can be expressed as

$$
\gamma=\left\{\begin{array}{l}
\frac{1-\gamma_{0}}{\tau_{1}} \cdot \tau+\gamma_{0}, 0 \leq \tau<\tau_{1} \\
1, \tau_{1} \leq \tau
\end{array}\right.
$$

The change rate of pore volume can be expressed as $[11,35]$ :

$$
\begin{gathered}
\frac{\Delta V}{V}=-\frac{1}{K}(\bar{\sigma}-\alpha p)+\varepsilon_{s}, \\
\frac{\Delta V_{p}}{V_{p}}=-\frac{1}{K_{p}}(\bar{\sigma}-\alpha p)+\gamma \varepsilon_{s},
\end{gathered}
$$

where $V=V_{p}+V_{s}, V$ is total volume of porous coal, $V_{p}$ is the pore volume of porous coal, and $V_{s}$ is solid volume of porous coal. $\bar{\sigma}$ is the mean compressive stress, $\alpha$ is the Biot coefficient, $p$ is the gas pressure. $\varepsilon_{s}$ is the gas
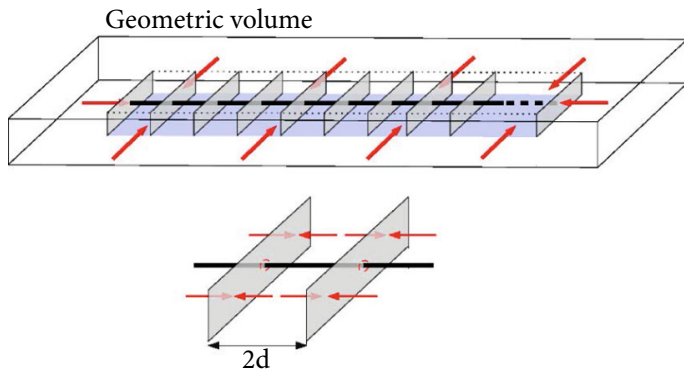

Figure 2: Schematic diagram of the artificial fracturing structure.

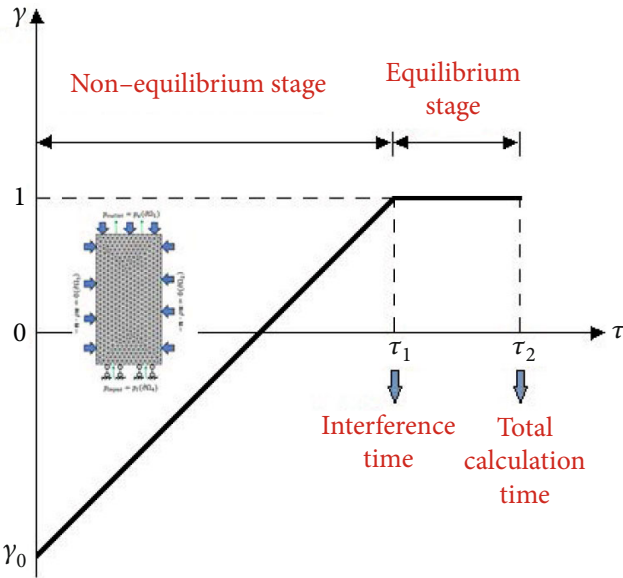

FIGURE 3: Schematic diagram of the change of adsorption strain ratio $\gamma$.

sorption-induced strain, $K$ is the bulk modulus of coal, and $K_{p}$ is the bulk modulus of pores.

$$
\begin{aligned}
K_{p} & =\frac{\phi}{\alpha} K, \\
\frac{\Delta V}{V} & =\frac{\Delta V_{s}}{V_{s}}+\frac{\Delta \phi}{1-\phi}, \\
\frac{\Delta V_{p}}{V_{p}} & =\frac{\Delta V_{s}}{V_{s}}+\frac{\Delta \phi}{\phi(1-\phi)},
\end{aligned}
$$


where $\phi$ is the porosity of coal. Combined Eq.(6)-(10), we obtain

$$
\begin{aligned}
\Delta \phi & =\phi(\bar{\sigma}-\alpha p)\left[-\frac{1}{K_{p}}+\frac{1}{K}\right]+\phi(\gamma-1) \varepsilon_{s} \\
& =\frac{\phi-\alpha}{K}(\bar{\sigma}-\alpha p)+\phi(\gamma-1) \varepsilon_{s} .
\end{aligned}
$$
obtain

Substitute $\varepsilon_{v}=-(1 / K)(\bar{\sigma}-\alpha p)+\varepsilon_{s}$ into Eq.(11), we

$$
\Delta \phi=(\alpha-\phi)\left(\varepsilon_{v}-\varepsilon_{s}+\frac{p}{K_{s}}\right)+\phi(\gamma-1) \varepsilon_{s},
$$

where $K_{s}$ is the bulk modulus of coal grains. Then,

$$
\begin{aligned}
\phi-\phi_{0} & =(\alpha-\phi)\left(S-S_{0}\right)+\phi(\gamma-1)\left(\varepsilon_{s}-\varepsilon_{s 0}\right) \\
& =(\alpha-\phi)\left(S-S_{0}\right)+\phi(\gamma-1)\left(\varepsilon_{s}-\varepsilon_{L} \frac{p_{0}}{P_{L}+p_{0}}\right),
\end{aligned}
$$

where $S=\varepsilon_{v}+\left(p / K_{s}\right)-\varepsilon_{s}, S_{0}=\left(p_{0} / K_{s}\right)-\varepsilon_{L} p_{0} /\left(p_{0}+p_{L}\right), p_{0}$ is the initial gas pressure, $\varepsilon_{s 0}$ is initial gas sorptioninduced strain, $p_{L}$ is the Langmuir pressure coefficient, and $\varepsilon_{L}$ is the Langmuir volumetric strain constant; so, we obtain

$$
\phi=\frac{\phi_{0}+\alpha\left(S-S_{0}\right)}{1+\left(S-S_{0}\right)-(\gamma-1)\left(\varepsilon_{s}-\varepsilon_{L}\left(p_{0} / P_{L}+p_{0}\right)\right)} .
$$

Find the partial derivatives of the equations on both sides of Eq. (11):

$$
\frac{\partial \phi}{\partial t}=\frac{\alpha-2 \phi+\phi \gamma}{1+2 S-\gamma S-S_{0}} \frac{\partial S}{\partial t} .
$$

The governing equations of gas flow can be expressed as

$$
\left[\phi+\frac{\rho_{c} p_{a} V_{L} P_{L}}{\left(p+P_{L}\right)^{2}}\right] \frac{\partial p}{\partial t}+p \frac{\partial \phi}{\partial t}-\nabla \cdot\left(\frac{k}{\mu} p \nabla p\right)=Q_{s}
$$

where $V_{L}$ is the Langmuir volume coefficient, $k$ is the permeability, $\mu$ is the gas viscosity, and $Q_{s}$ is source term of gas flow, $Q_{s}=\omega\left(p_{f}-p_{m}\right)$. Experiments $[11,12]$ show that the relationship between porosity and permeability of coal can be expressed as

$$
\frac{k}{k_{0}}=\left(\frac{\phi}{\phi_{0}}\right)^{3} .
$$

Combined Eq. (16) with Eq.(17), we can obtain the permeability of the pore system and fracture system:

$$
k_{m}=k_{m 0}\left[\frac{\phi_{m 0}+\alpha\left(S_{m}-S_{m 0}\right)}{1+\left(S_{m}-S_{m 0}\right)-(\gamma-1)\left(\varepsilon_{m s}-\varepsilon_{L}\left(p_{m 0} / P_{L}+p_{m 0}\right)\right)} \cdot \frac{1}{\phi_{m 0}}\right]^{3},
$$

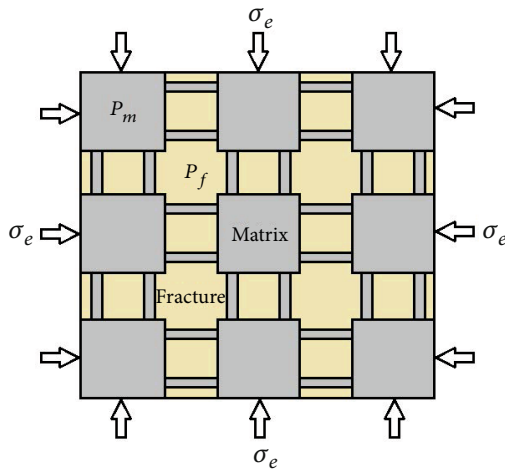

FIGURE 4: Dual porosity coal structure.

$$
k_{f}=k_{f 0}\left[\frac{\phi_{f 0}+\alpha\left(S_{f}-S_{f 0}\right)}{1+\left(S_{f}-S_{f 0}\right)-(\gamma-1)\left(\varepsilon_{f s}-\varepsilon_{L}\left(p_{f 0} / P_{L}+p_{f 0}\right)\right)} \cdot \frac{1}{\phi_{f 0}}\right]^{3},
$$

where subscript $m$ denotes matrix and $f$ denotes fractures.

2.2. Governing Equation of Coal Deformation. The structure of the dual porosity model is shown in Figure 4. The equilibrium equation of matrix and fracture can be expressed as

$$
\sigma_{i j}+f_{i}=0,
$$

where $\sigma_{i j}$ is the component of stress tensor, and $f_{i}$ is the component of body force. The relationship between coal deformation and stress induced by adsorption can be expressed as [36]

$$
\varepsilon_{i j}=\frac{1}{2 G} \sigma_{i j}-\left(\frac{1}{6 G}-\frac{1}{9 k}\right) \sigma_{k k} \delta_{i j}+\frac{\alpha}{3 K} p \delta_{i j}+\frac{\varepsilon_{s}}{3} \delta_{i j},
$$

where $G$ is the elastic shear modulus, $\sigma_{k k}=\sigma_{11}+\sigma_{22}+\sigma_{33}$, and $\delta_{i j}$ is the Kronecker delta. According to the Langmuir equation, the sorption-induced strain can be expressed as

$$
\varepsilon_{s}=\varepsilon_{L} \frac{p}{P_{L}+p} .
$$

Combined Eq. (19) with Eq. (20), the governing equation of coal deformation can be expressed as $[37,38]$

$$
G u_{i, k k}+\frac{G}{1-2 \mu} u_{k, k i}-\alpha p_{i}-K \varepsilon_{s, i}+f_{i}=0
$$

2.3. Governing Equation of Gas Flow. According to the state of occurrence, gas in the coal reservoir can be divided into two parts: the adsorption phase and the free phase. The total mass can be described by the following equations:

$$
m_{m}=\rho_{g m} \phi_{m}+\rho_{g a} \rho_{c} \frac{V_{L} p_{m}}{p_{m}+P_{L}},
$$




$$
m_{f}=\rho_{g f} \phi_{f}+\rho_{g a} \rho_{c} \frac{V_{L} p_{f}}{p_{f}+P_{L}}
$$

where $m_{m}$ and $m_{f}$, respectively, denote the mass of gas in matrix and fracture. $\rho_{g m}$ and $\rho_{g f}$, respectively, denote the gas density in matrix and fracture. $\rho_{g a}$ denotes the gas density in standard condition. $\rho_{c}$ denotes coal density. Based on the conservation law of mass, the governing equation of gas mass can be expressed as

$$
\frac{\partial m}{\partial t}+\nabla \cdot\left(\rho_{g} q_{g}\right)=Q_{s}
$$

where $t$ is the time. $\rho_{g}$ is the gas density, and $q_{g}$ is Darcy's flow velocity. Neglecting the effect of gravity, Darcy's flow can be expressed as

$$
\dot{q}_{g}=-\frac{k}{\mu} \nabla p
$$

where $\dot{q}_{g}$ represents the derivation of $q_{g}$. Substituting Eqs.(23), (24), and (26) into Eq.(25), the mass conservation equation of the gas can be expressed as $[11,39,40]$

$$
\begin{gathered}
{\left[\phi_{m}+\frac{\rho_{c} p_{a} V_{L} P_{L}}{\left(p_{m}+P_{L}\right)^{2}}\right] \frac{\partial p_{m}}{\partial t}+p_{m} \frac{\partial \phi_{m}}{\partial t}-\nabla \cdot\left(\frac{k_{m}}{\mu} p_{m} \nabla p_{m}\right)=Q_{s},} \\
{\left[\phi_{f}+\frac{\rho_{c} p_{a} V_{L} P_{L}}{\left(p_{f}+P_{L}\right)^{2}}\right] \frac{\partial p_{f}}{\partial t}+p_{f} \frac{\partial \phi_{f}}{\partial t}-\nabla \cdot\left(\frac{k_{f}}{\mu} p_{f} \nabla p_{f}\right)=-Q_{s},}
\end{gathered}
$$

where $p_{a}$ is the atmospheric pressure, $p_{a}=101.325 \mathrm{kPa}$.

2.4. Coupled Governing Equation. The dual porosity model proposed in this paper considers the pore strain induced by adsorption as a linear relationship with the bulk strain. The coal deformation governing equation is rewritten as

$$
G u_{i, k k}+\frac{G}{1-2 \mu} u_{k, k i}-\alpha p_{i}-\frac{K \varepsilon_{L} P_{L}}{\left(p+P_{L}\right)^{2}} p_{i}+f_{i}=0
$$

There is no deformation in the coal at initial pressure, and the porosity evolution equation in the gas injection process is

$$
\frac{\partial \phi}{\partial t}=\frac{\alpha-\phi}{1+S}\left[\frac{\partial \varepsilon_{v}}{\partial t}+\frac{1}{K_{s}} \frac{\partial p}{\partial t}-\frac{\varepsilon_{L} P_{L}}{\left(p+P_{L}\right)^{2}} \frac{\partial p}{\partial t}\right],
$$

where $\varepsilon_{v}=\varepsilon_{11}+\varepsilon_{22}+\varepsilon_{33}$ is the volume strain of coal. Substituting Eq. (8) for Eq. (5), we obtain the coal bed gas flow equation of the pore system and fracture system:
TABlE 1: Property parameters of simulation model against experimental data.

\begin{tabular}{lc}
\hline Parameter & Value \\
\hline Young's modulus of coal, $E(\mathrm{MPa})$ & 3600 \\
Possion's ratio of coal, $v$ & 0.35 \\
Density of coal, $\rho_{c}\left(\mathrm{~kg} / \mathrm{m}^{3}\right)$ & $1.25 \times 10^{3}$ \\
Density of methane, $\rho_{g}\left(\mathrm{~kg} / \mathrm{m}^{3}\right)$ & 1.784 \\
Methane dynamic viscosity, $\mu(\mathrm{Pa} \cdot \mathrm{s})$ & $1.493 \times 10^{-5}$ \\
Langmuir pressure constant, $P_{L}(\mathrm{MPa})$ & 1.43 \\
Langmuir volumetric strain constant, $\varepsilon_{L}$ & 0.004 \\
Hydraulic diffusivity of gas, $\lambda_{i}\left(\mathrm{~m}^{2} / \mathrm{s}\right)$ & $1.42 \times 10^{-7}$ \\
Distance between two hydro fractures spaced, $2 d(\mathrm{~m})$ & 8 \\
Cleat compressibility, $C_{f}\left(\mathrm{MPa}^{-1}\right)$ & $3.2 \times 10^{-7}$ \\
\hline
\end{tabular}

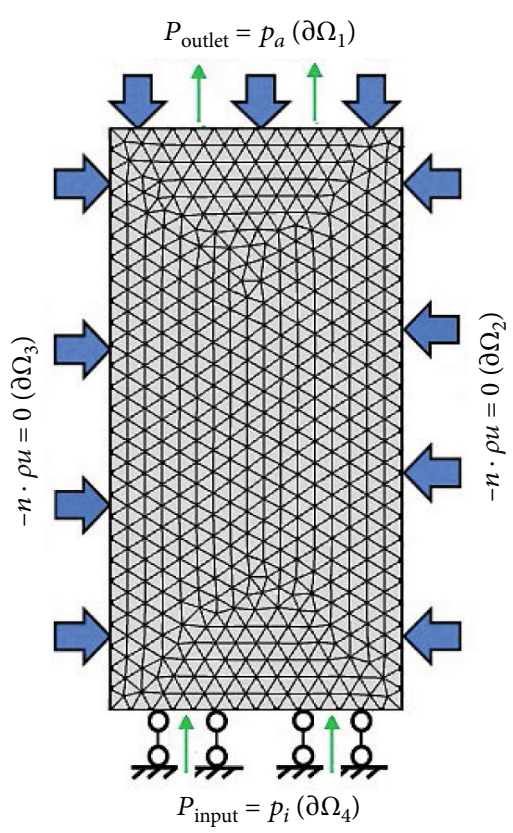

Figure 5: Simulation model for the case of $\mathrm{CO}_{2}$ injection.

$$
\begin{aligned}
& {\left[\phi_{m}+\frac{\rho_{m c} p_{a} V_{L} P_{L}}{\left(p_{m}+P_{L}\right)^{2}}+\frac{\left(\alpha-\phi_{m}\right) p_{m}}{\left(1+S_{m}\right) K_{s}}-\frac{\left(\alpha-\phi_{m}\right) \varepsilon_{L} P_{L} p_{m}}{\left(1+S_{m}\right)\left(p_{m}+P_{L}\right)^{2}}\right] \frac{\partial p_{m}}{\partial t}} \\
& -\nabla \cdot\left(\frac{k_{m}}{\mu} p_{m} \nabla p_{m}\right)=Q_{s}-\frac{\left(\alpha-\phi_{m}\right)_{L} p_{m}}{\left(1+S_{m}\right)} \frac{\partial \varepsilon_{v}}{\partial t}
\end{aligned}
$$

$$
\begin{gathered}
{\left[\phi_{f}+\frac{\rho_{f c} p_{a} V_{L} P_{L}}{\left(p_{f}+P_{L}\right)^{2}}+\frac{\left(\alpha-\phi_{f}\right) p_{f}}{\left(1+S_{f}\right) K_{s}}-\frac{\left(\alpha-\phi_{f}\right) \varepsilon_{L} P_{L} p_{f}}{\left(1+S_{f}\right)\left(p_{f}+P_{L}\right)^{2}}\right] \frac{\partial p_{f}}{\partial t}} \\
-\nabla \cdot\left(\frac{k_{f}}{\mu} p_{f} \nabla p_{f}\right)=-Q_{s}-\frac{\left(\alpha-\phi_{f}\right)_{L} p_{f}}{\left(1+S_{f}\right)} \frac{\partial \varepsilon_{v}}{\partial t} .
\end{gathered}
$$




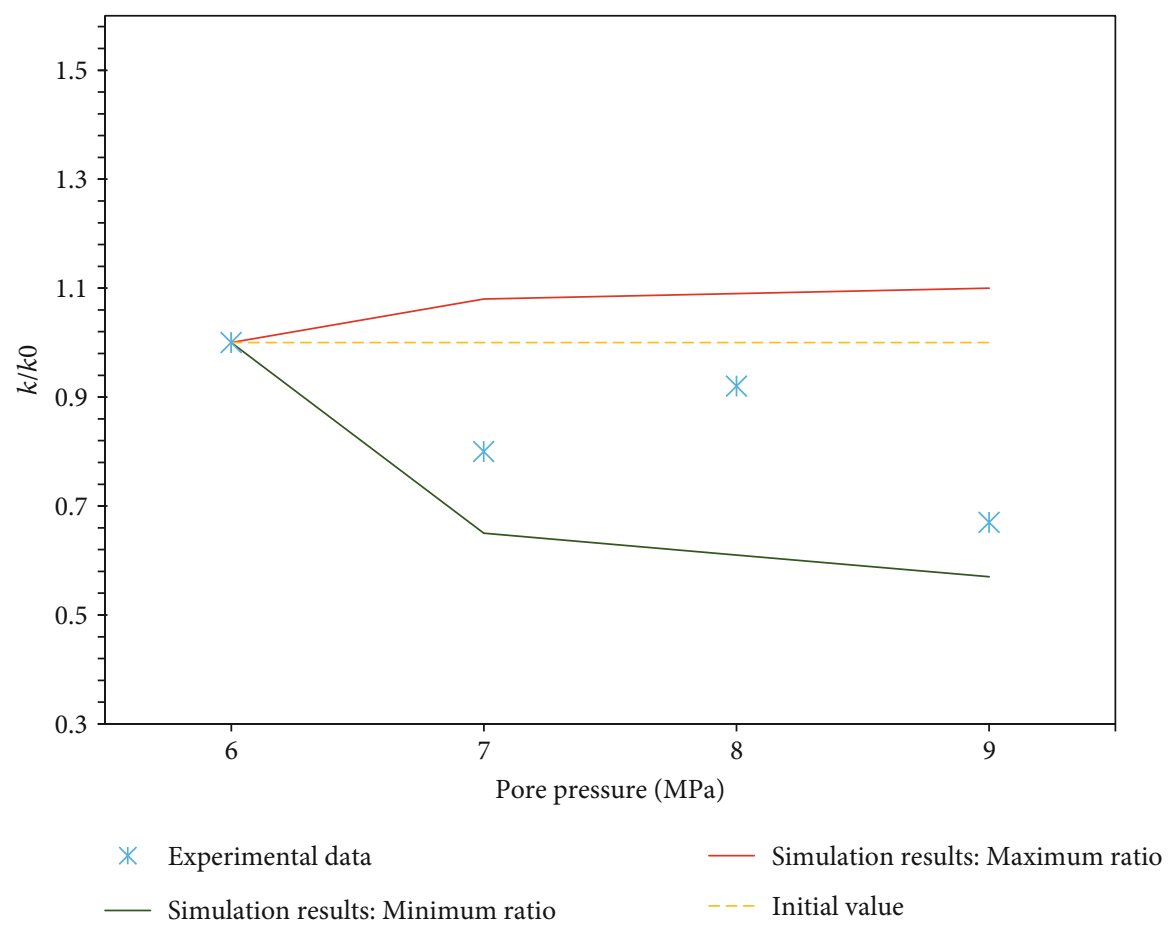

FIGURE 6: Comparison between experimental data and simulation results for the case of confining pressure $p=24 \mathrm{MPa}$.

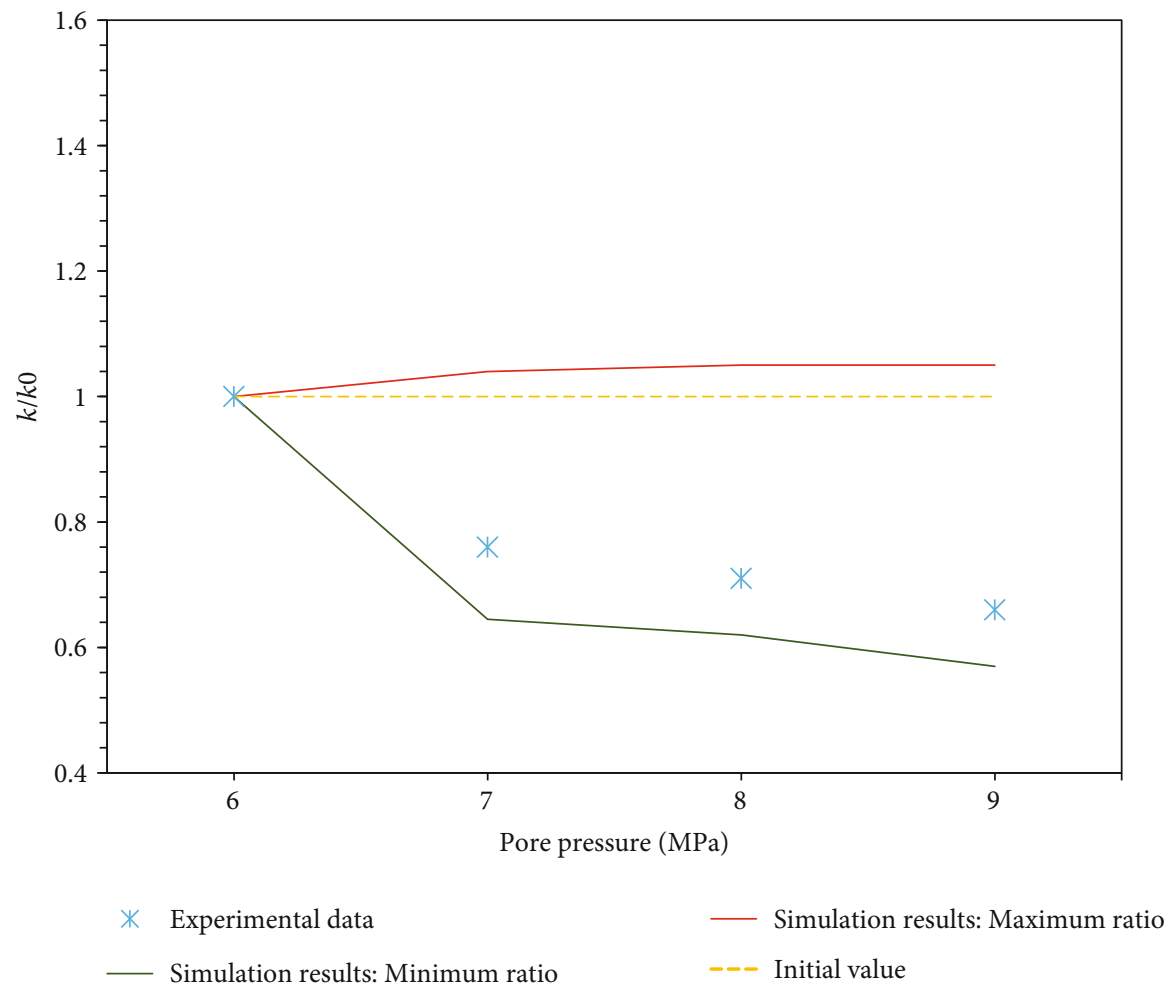

FigURE 7: Comparison between experimental data and simulation results for the case of confining pressure $p=20 \mathrm{MPa}$. 


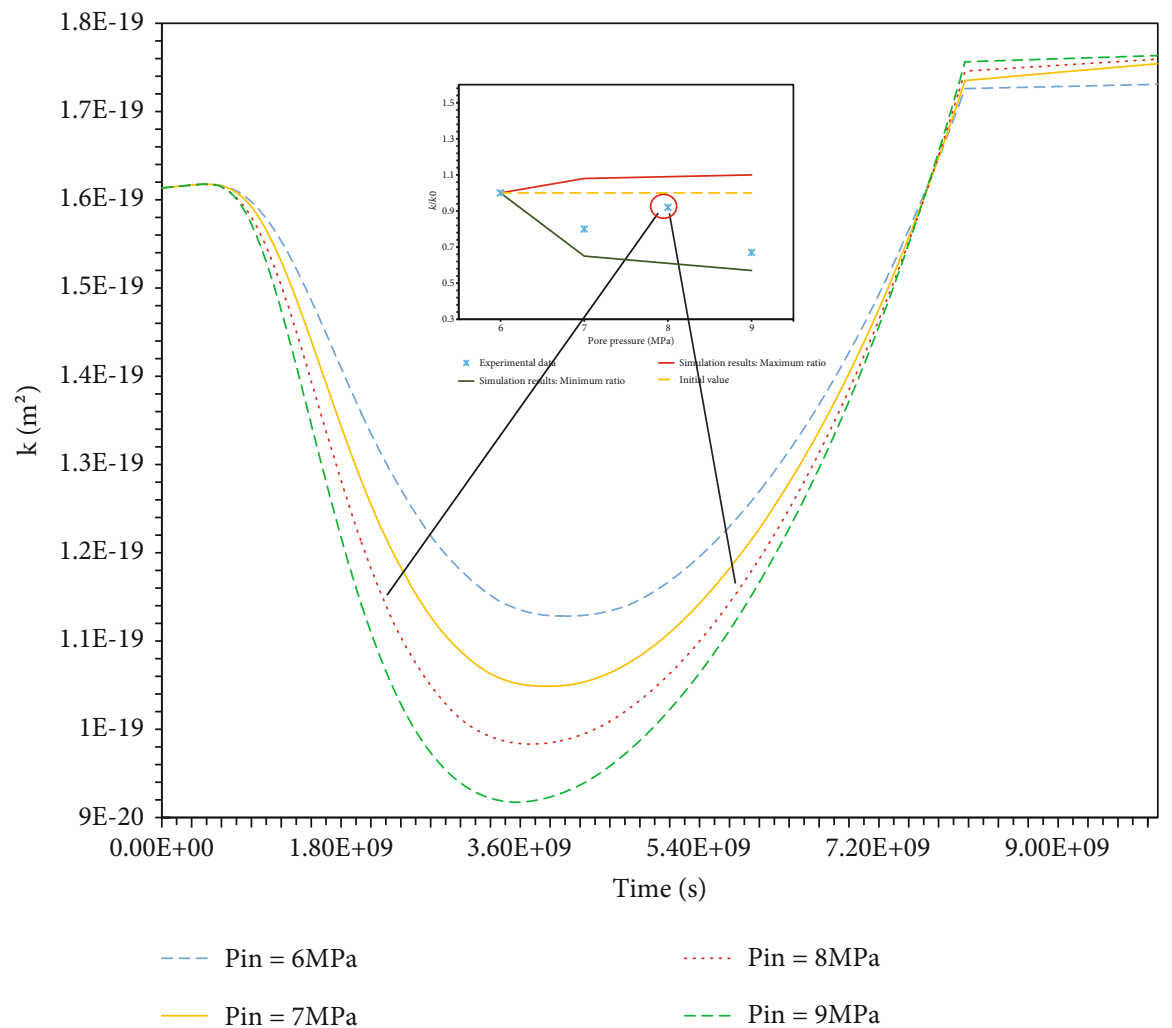

FIGURE 8: Evolution of permeability with different injection pressures for the case of confining pressure $p=24 \mathrm{MPa}$.

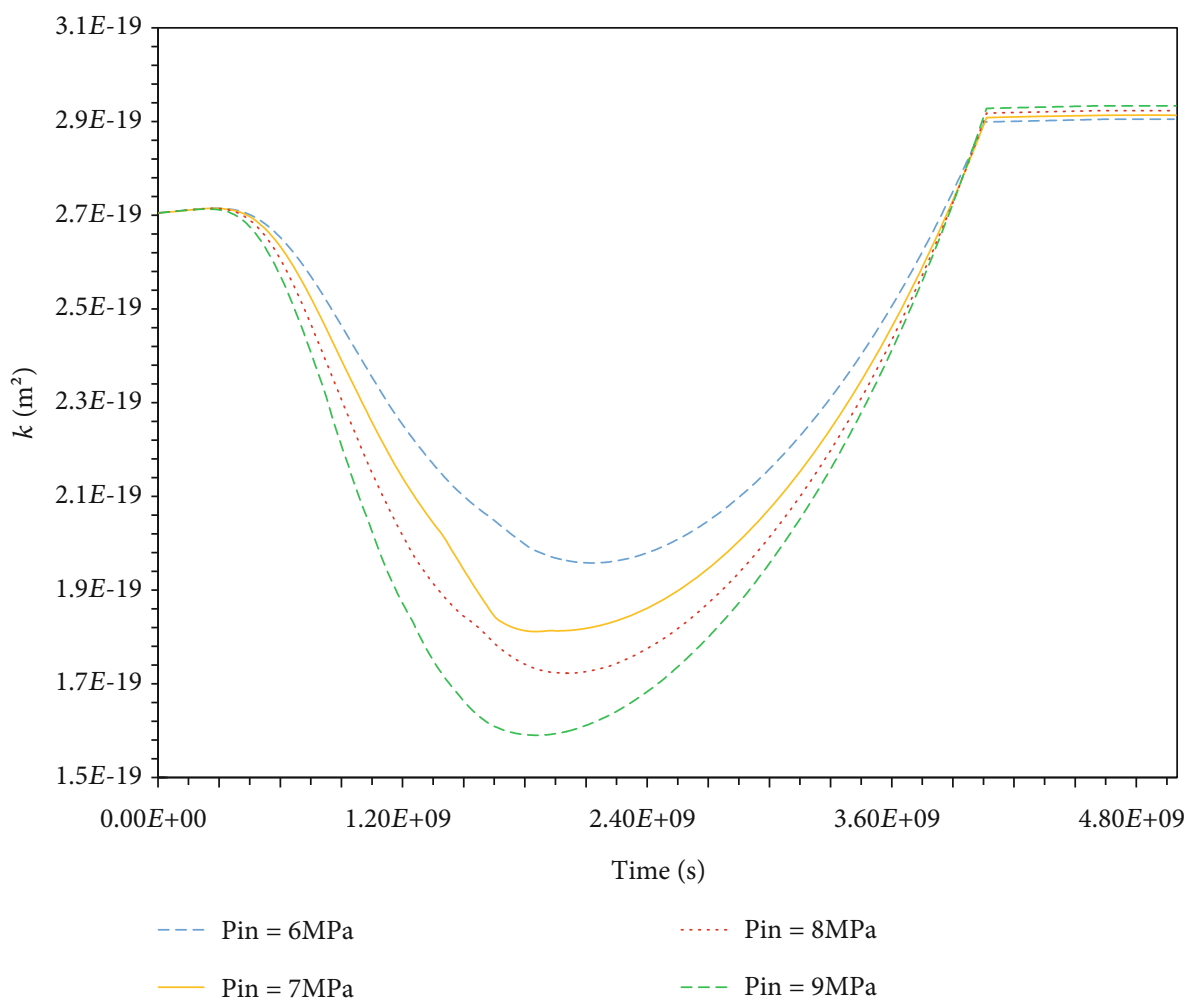

FigURE 9: Evolution of permeability with different injection pressures for the case of confining pressure $p=20 \mathrm{MPa}$. 


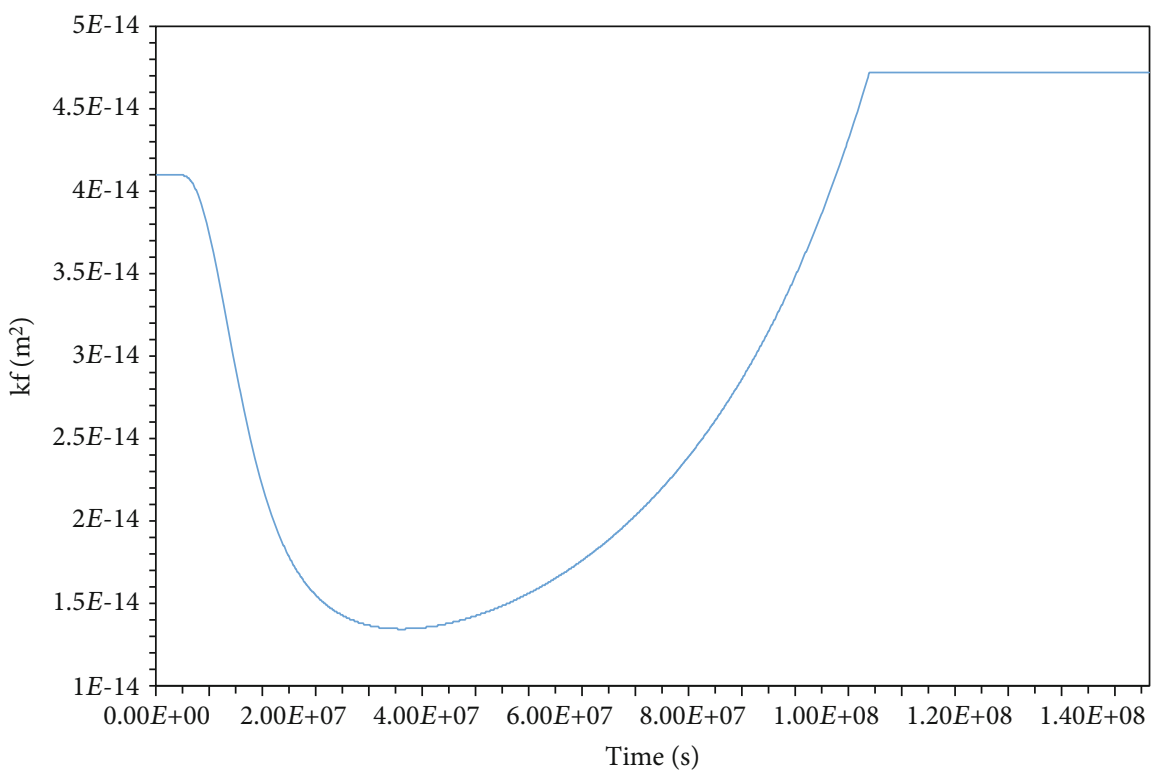

FIGURE 10: Permeability evolution process of fracture system of model I.

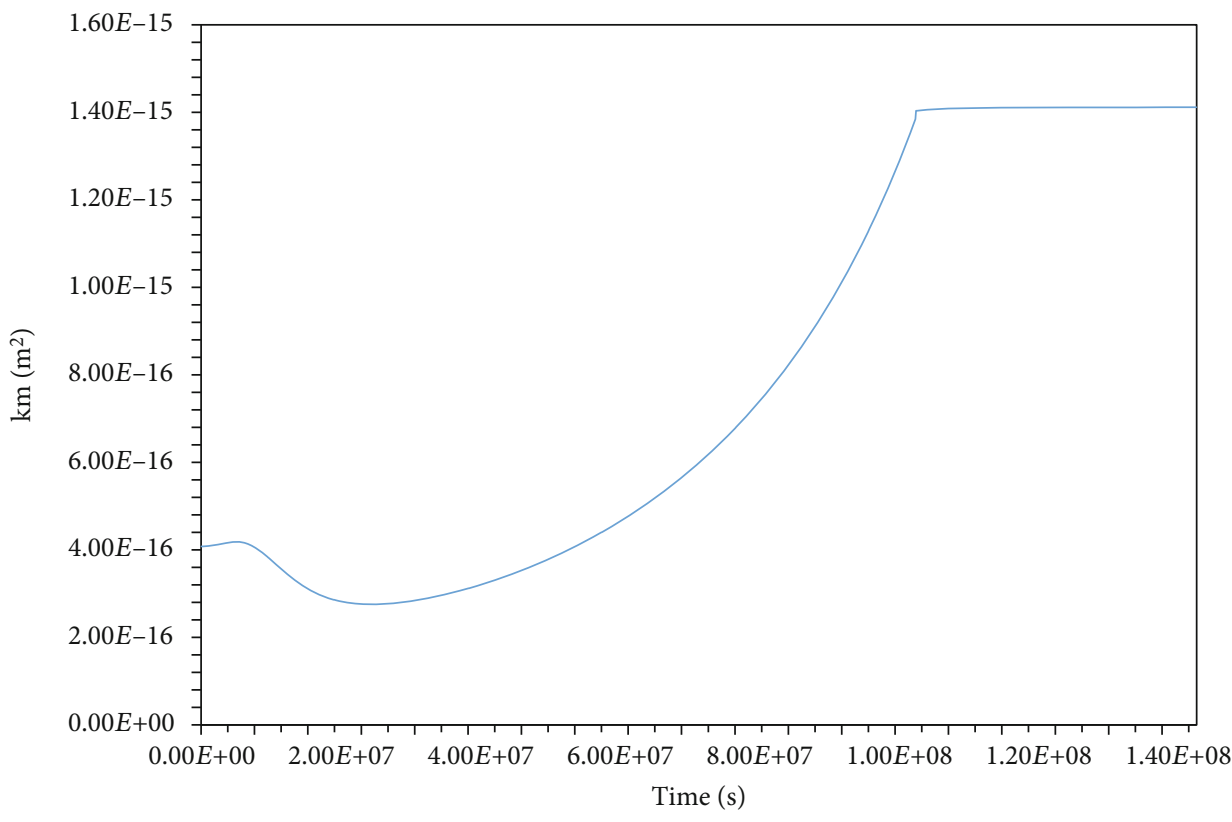

FIGURE 11: Permeability evolution process of pore system of model I.

\section{Model Verifications against Experimental Data}

The process of gas seepage in dual porosity media is highly nonlinear both in time and space. The governing equations of gas seepage in dual porosity media are partial differential equations, which are difficult to obtain analytical solutions. In this paper, the multiphysical coupling software COMSOL is used for numerical solution. In order to verify the correctness of the model, we compare the simulation results with the experimental data [41].The material property parameters used in the calculation model are shown in Table 1.
The simulation model is a square domain with the size of $0.076 \mathrm{~m} \times 0.038 \mathrm{~m}$. $\mathrm{CO}_{2}$ is injected at the bottom of the model, and the outlet is the upper boundary. The gas injection pressure varies from $6 \mathrm{MPa}$ to $9 \mathrm{MPa}$. The bottom boundary is hinge constraint, and the upper, left, and right boundaries are uniformly distributed, as shown in Figure 5. The numerical results are compared with two sets of laboratory data (confining pressure $24 \mathrm{MPa}$ and $20 \mathrm{MPa}$, respectively), as shown in Figures 6 and 7 . The two experimental cases are simulated as follows: the permeability evolution process of each experiment from the initial equilibrium state to the final equilibrium state is calculated (Figures 8 and 9). The red lines in Figures 6 and 
8 represent the upper limit of permeability simulation results under different injection pressures, and the green lines represent the lower limit of permeability simulation results. It is found that the experimental results may not reach the equilibrium state of permeability evolution.

According to Figures 6 and 7, the coupling model proposed in this paper is in good agreement with the experimental data. According to Figures 8 and 9, the evolution of permeability in $\mathrm{CO}_{2}$ gas injection can be divided into four stages: (1) when $\mathrm{CO}_{2}$ is injected into coal, the pore space becomes larger, and the permeability increases with the increase of fracture pressure. (2) The gas pressure in fracture is larger than that in matrix. The gas begins to diffuse from fracture to matrix. The volume of the matrix expands, the volume of the fracture shrinks, and the permeability of coal decreases. (3) With the gradual diffusion of gas into the matrix, only local expansion deformation has an impact on the permeability of coal, and the permeability increases gradually, and (4) the pressure of the matrix and pore is in equilibrium with each other, the coal mass is uniformly expanded, and the coupling process is stable.

From Figures 6 and 7, it can be seen that coal permeability is affected by the injection pressure. Figures 8 and 9 correspond to the evolution of permeability with time under different injection pressures of Figures 6 and 7 , respectively. Each point of the measured data in Figures 6 and 7 corresponds to the specific location of the corresponding curve in Figures 8 and 9. Because the curve is not monotonous, the measured data mostly correspond to the two points of the curve, as shown in Figure 8 . When the gas injection reaches the final stable state, the permeability value is the upper limit of the permeability curve. Figures 6 and 7 show that the measured permeability values lie between the upper and lower limits, indicating that the measured permeability values may not reach the final equilibrium state, which may due to the low porosity of coal samples. The permeability evolution process of the fracture and pore system of model I is not a monotone line, which can be seen in Figures 10 and 11 .

\section{Numerical Experiments}

4.1. Permeability Tests under the Condition of Constant Confining Stress. The boundary conditions of the numerical model are shown in Figure 5. The gas parameters of dual porosity coal are shown in the following table, which comes from previous experiments (Robertson E.P. and Christiansen R.L., 2005). The size of the calculation model is $0.1 \mathrm{~m} \times$ $0.05 \mathrm{~m}$. The lower boundary is fixed hinge constraint, and the upper, left, and right boundaries are subjected to uniform pressure $7 \mathrm{MPa}$. There is no mass transfer on the left boundary and the right boundary. $\mathrm{CO}_{2}$ is injected from the bottom of the model and outflows from the upper boundary. The inlet pressure is $4.8 \mathrm{MPa}$, and outlet pressure is atmospheric pressure. The parameters of coal and gas for simulation are shown in Table 2.

The permeability evolution process of the coal fracture system and pore system is shown in Figures 5 and 6 . Accord-
TABle 2: Property parameters of coal and gas.

\begin{tabular}{lc}
\hline Parameter & Value \\
\hline Young's modulus of coal, $E(\mathrm{MPa})$ & 5100 \\
Possion's ratio of coal, $v$ & 0.39 \\
Density of coal, $\rho_{c}\left(\mathrm{~kg} / \mathrm{m}^{3}\right)$ & $1.25 \times 10^{3}$ \\
Density of methane, $\rho_{g}\left(\mathrm{~kg} / \mathrm{m}^{3}\right)$ & 1.784 \\
Methane dynamic viscosity, $\mu(\mathrm{Pa} \cdot \mathrm{s})$ & $1.493 \times 10^{-5}$ \\
Langmuir pressure constant, $P_{L}(\mathrm{MPa})$ & 2.75 \\
Langmuir volumetric strain constant, $\varepsilon_{L}$ & 0.01 \\
Hydraulic diffusivity of gas, $\lambda_{i}\left(\mathrm{~m}^{2} / \mathrm{s}\right)$ & $1.1 \times 10^{-7}$ \\
Distance between two hydro fractures spaced, $2 d(\mathrm{~m})$ & 7 \\
Cleat compressibility, $C_{f}\left(\mathrm{MPa}^{-1}\right)$ & $1.04 \times 10^{-7}$ \\
\hline
\end{tabular}

TABle 3: Simulation strategies.

Case 1 Impact of adsorptive strain ratios on the resulting response $\gamma=-100,-150,-200$

Case 2 Impact of interference time on the resulting response $\tau=7 \times 10^{7}, 9 \times 10^{7}, 1.1 \times 10^{8} \mathrm{~s}$

Case 3 Impact of gas injection pressure on the resulting response $P_{\text {in }}=4.1,4.8$, and $5.5 \mathrm{MPa}$

ing to Figures 5 and 6, during the process of gas injection, the permeability change rule of the pore system and fracture system is similar, which includes four stages: increasing, decreasing, then gradually restoring, and finally balancing. The permeability of the pore system is changing more obviously. The reason is that the porosity of pore system is small, and the small change of pore volume will have a more obvious impact on its permeability.

In this paper, a dual porosity model considering the adsorption strain ratio is proposed. The effects of three main factors on permeability evolution during gas injection are analyzed, including

(1) Adsorption strain ratio

(2) Interference time

(3) Gas injection pressure

The simulation parameters of different cases are shown in Table 3. The evolution of permeability with different adsorptive strain ratios during gas injection is shown in Figures 1214. According to Figures 12-14 below, although the adsorption strain ratio does not affect the permeability after the final equilibrium state of gas injection, the lower limit of permeability decreases obviously when the absolute value of the adsorption strain ratio increases.

The comparison of the evolution process of permeability with the interference time is shown in Figure 13. According to Figure 13, we obtain that the difference of permeability is mainly the lower limit of the permeability evolution process 


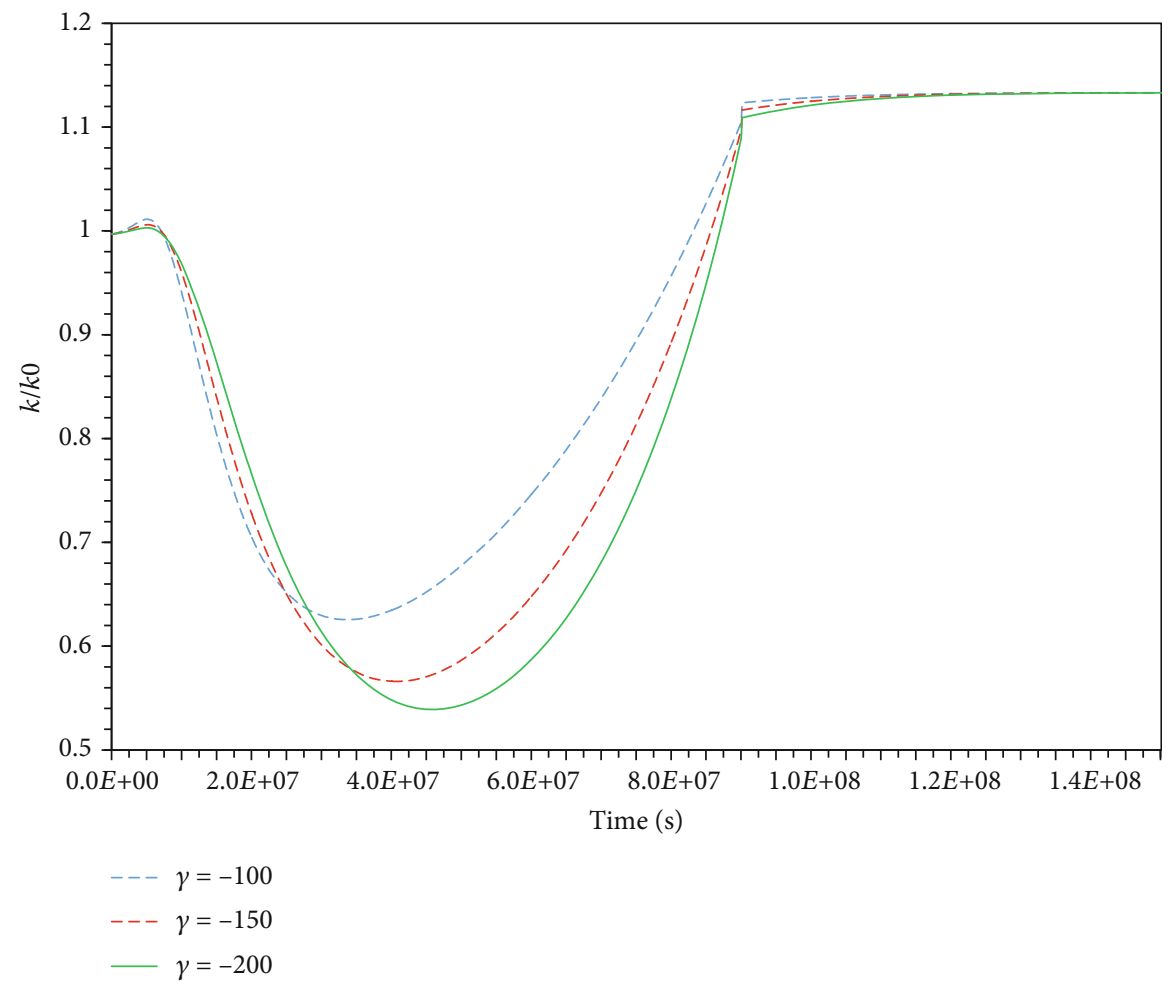

FIgURE 12: Evolution of permeability with different $\gamma$ of model I.

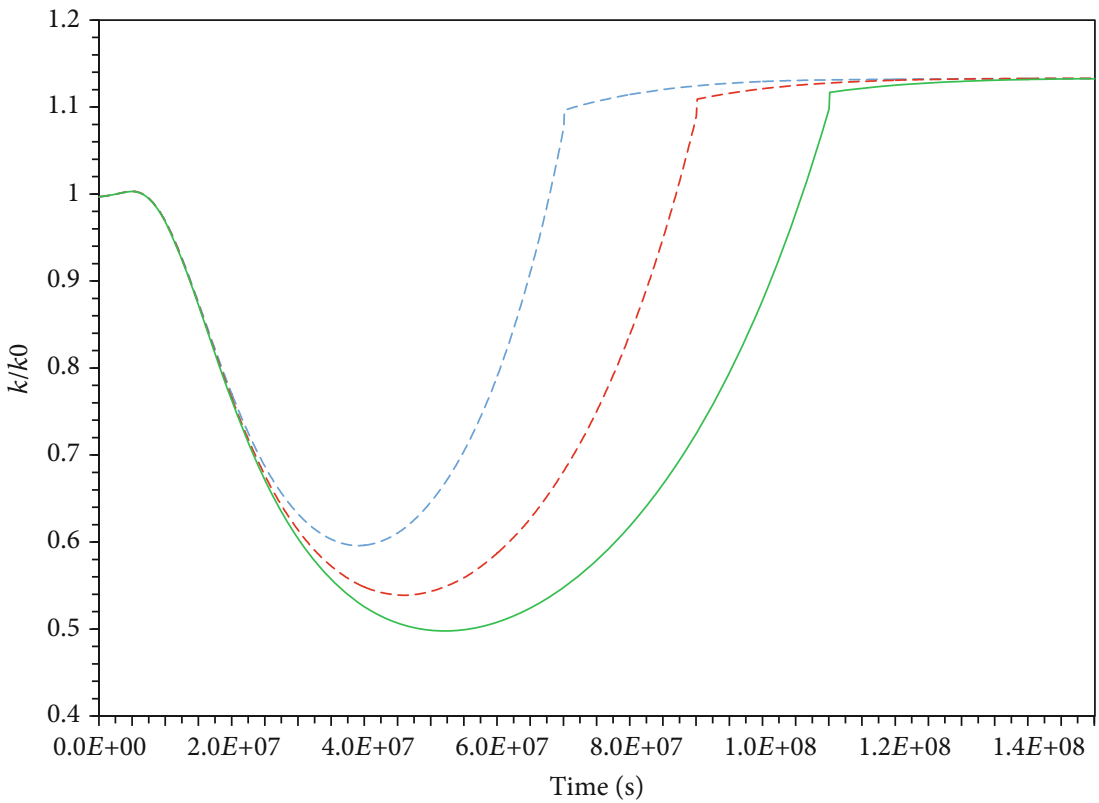

$\begin{aligned}--- & \text { Interference time }=7.0 \mathrm{e} 7 \mathrm{~s} \\ ---\quad & \text { Interference time }=9.0 \mathrm{e} 7 \mathrm{~s} \\ \text { - Interference time } & =1.1 \mathrm{e} 8 \mathrm{~s}\end{aligned}$

FIGURE 13: Evolution of permeability with different interference times of model I.

when the coal interference time is different. And the lower limit of permeability is inversely proportional to the stable time required for gas diffusion in the coal.
When the confining pressure is maintained at $7 \mathrm{MPa}$, the evolution of coal permeability with gas injection pressure is shown in Figure 14. It can be seen from Figure 14 


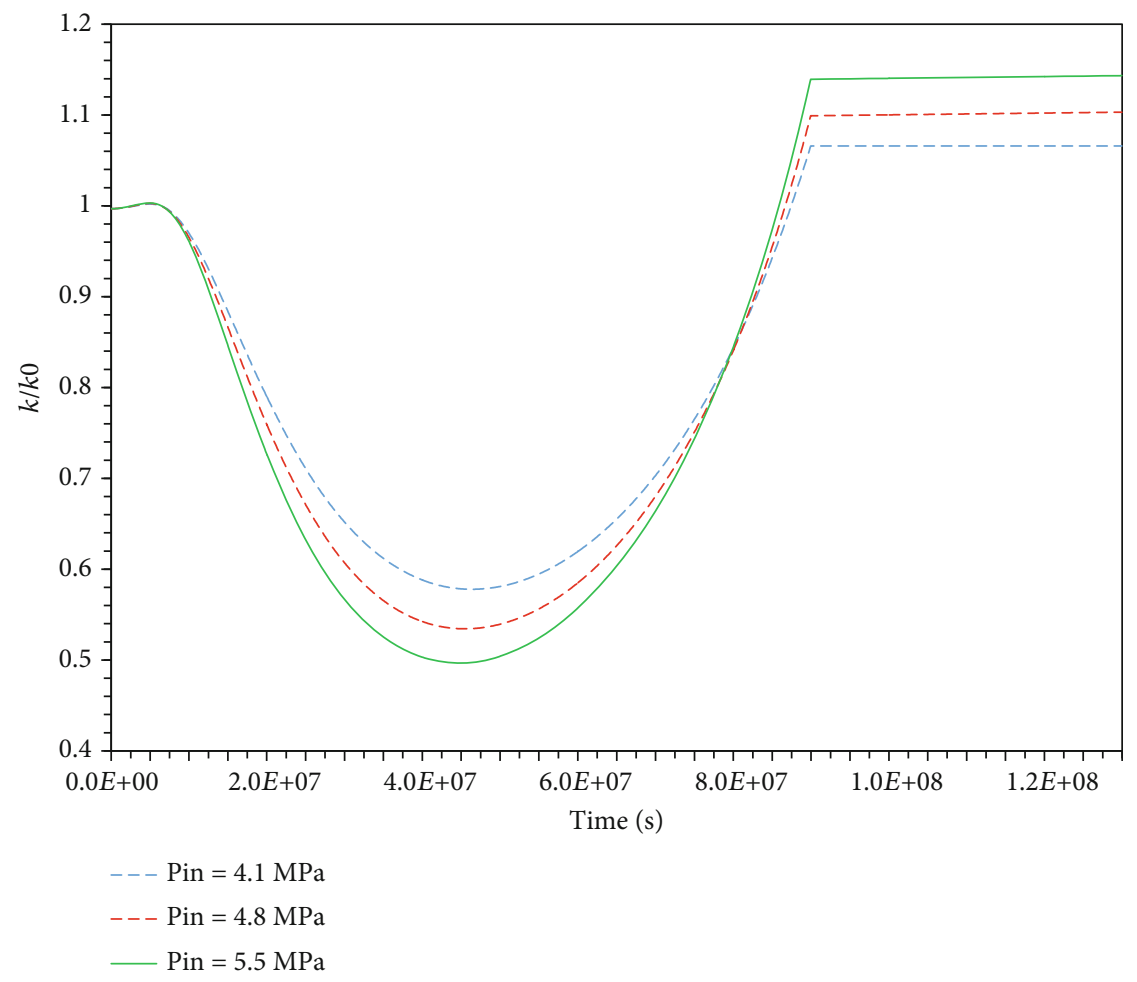

FIGURE 14: Evolution of permeability with different injection pressures of model I.

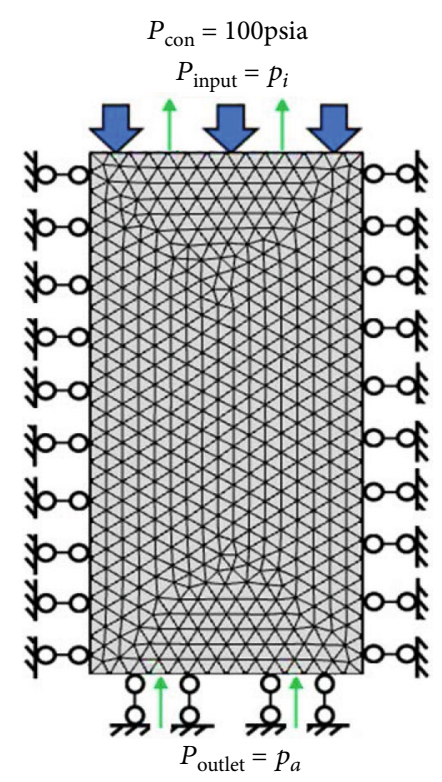

FIGURE 15: Simulation model II for the case of gas injection.

that with the increase of the injection pressure, the lower limit of permeability value gradually decreases, and the upper limit gradually increases in the process of coal permeability evolution. The upper limit is at the final equilibrium state of the curve.
TABLE 4: Property parameters of coal and gas.

\begin{tabular}{lc}
\hline Parameter & Value \\
\hline Young's modulus of coal, $E(\mathrm{MPa})$ & 4900 \\
Possion's ratio of coal, $v$ & 0.39 \\
Density of coal, $\rho_{c}\left(\mathrm{~kg} / \mathrm{m}^{3}\right)$ & $1.25 \times 10^{3}$ \\
Density of methane, $\rho_{g}\left(\mathrm{~kg} / \mathrm{m}^{3}\right)$ & 1.784 \\
Methane dynamic viscosity, $\mu(\mathrm{Pa} \cdot \mathrm{s})$ & $1.493 \times 10^{-5}$ \\
Langmuir pressure constant, $P_{L}(\mathrm{MPa})$ & 2.69 \\
Langmuir volumetric strain constant, $\varepsilon_{L}$ & 0.008 \\
Hydraulic diffusivity of gas, $\lambda_{i}\left(\mathrm{~m}^{2} / \mathrm{s}\right)$ & $9.35 \times 10^{-11}$ \\
Cleat compressibility, $C_{f}\left(\mathrm{MPa}^{-1}\right)$ & $7.5 \times 10^{-8}$ \\
\hline
\end{tabular}

4.2. Permeability Tests under the Condition of Three Roller Constrains. The boundary condition of model II is shown in Figure 15. The property parameters are shown in Table 4. Evolution of the coal fracture and pore permeability under the condition of three roller constrains is shown in Figures 16 and 17.

According to Figures 16 and 17, it can be seen that the fracture system and pore system of coal of model II in the process of gas injection also include four stages: first rising, decreasing, restoring, and finally balancing. The change of permeability of pore system is more obvious. 


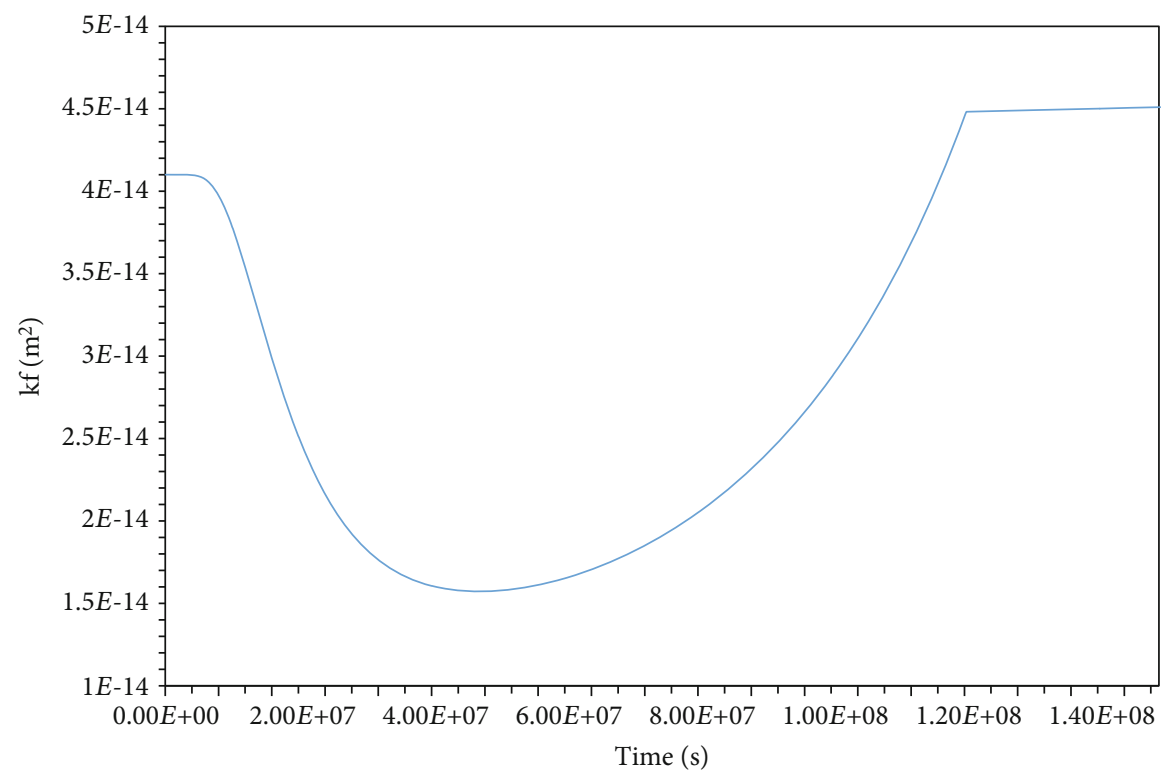

FIGURE 16: Permeability evolution process of the fracture system of model II.

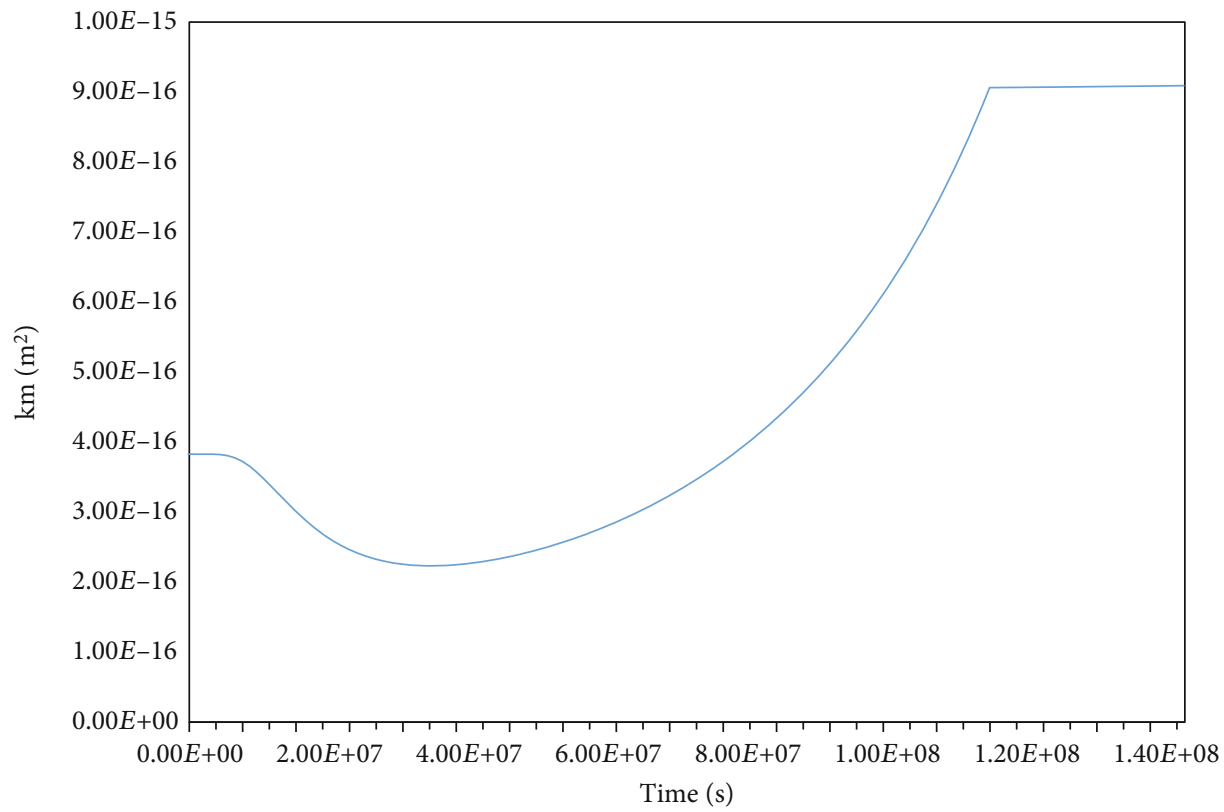

FIGURE 17: Permeability evolution process of the pore system of model II.

The simulation parameters of different cases are shown in Table 5.

The influence of coal adsorption strain ratio $\gamma$ on the permeability evolution process in the $\mathrm{CO}_{2}$ injection process of model II is shown in Figure 18. According to Figure 18, the permeability after final equilibrium is the same under different adsorption strain ratios. The lower limit of permeability is proportional to $\gamma$.

The evolution process of the permeability of model II varies with the interference time is shown in Figure 19. It can be seen from Figure 19 that with the increase of coal
TABle 5: Simulation strategies.

Case 1 Impact of adsorptive strain ratios on the resulting response $\gamma=-100,-150,-200$

Case 2 Impact of interference time on the resulting response $\tau=7.6 \times 10^{7}, 9.6 \times 10^{7}, 1.16 \times 10^{8} \mathrm{~s}$

Case 3 Impact of gas injection pressure on the resulting response $P_{\text {in }}=4.1,4.8$, and $5.5 \mathrm{MPa}$ 


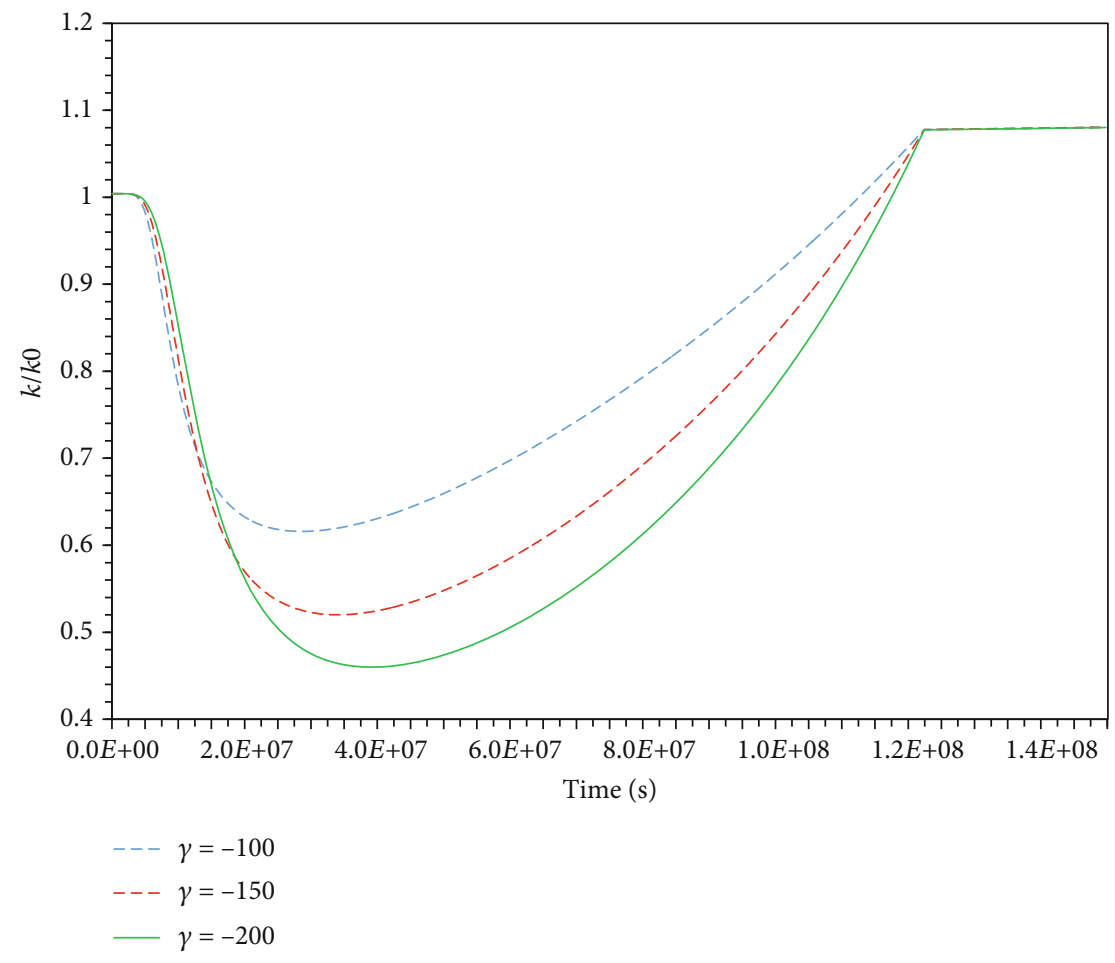

FIGURE 18: Evolution of permeability with different $\gamma$ of model II.

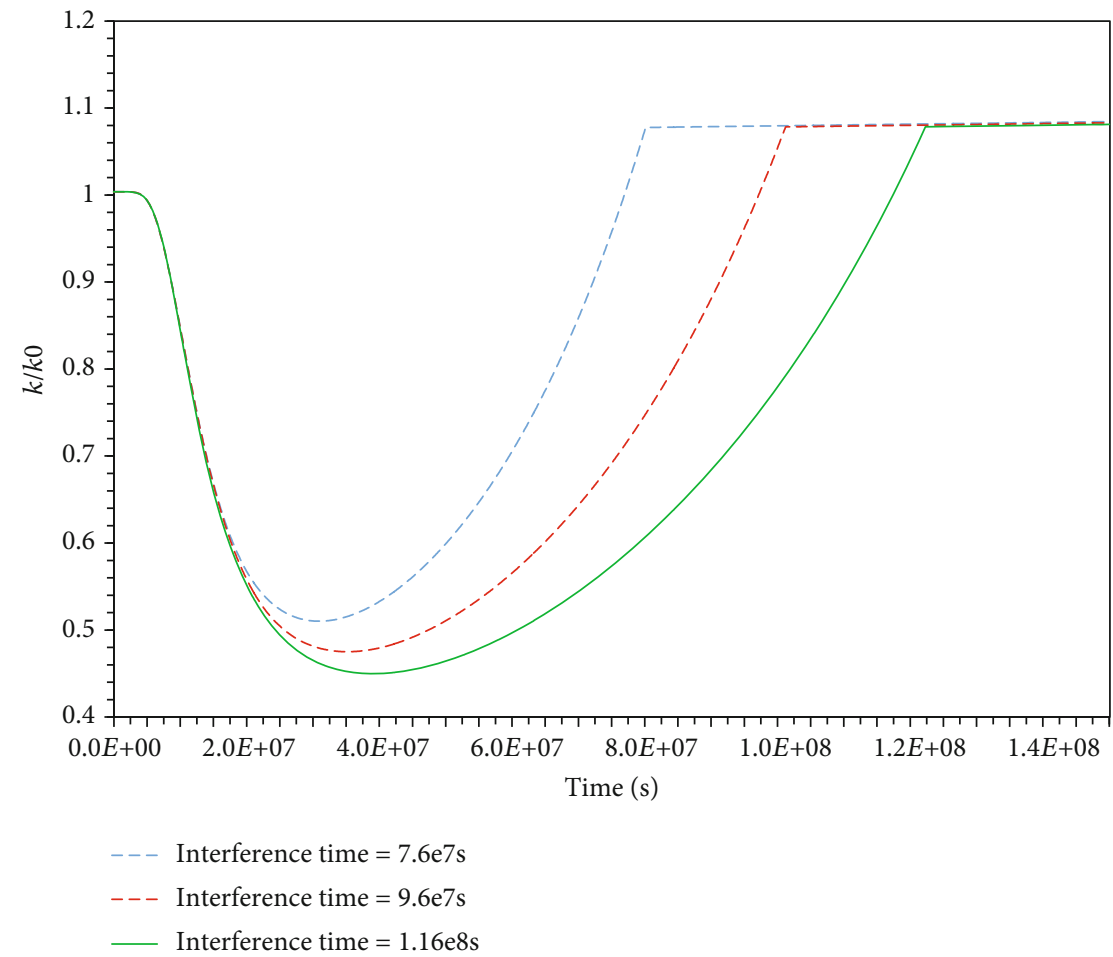

FIGURE 19: Evolution of permeability with different interference times of model II.

interference time, the lower limit of the permeability curve gradually decreases; that is, the change of coal porosity is more obvious. However, due to the constant gas injection pressure, when the coupling process of coal deformation and gas permeability is eventually balanced, the permeability of coal with different interference times is unchanged.

The evolution process of permeability under different gas injection pressures is shown in Figure 20. It can be seen from 


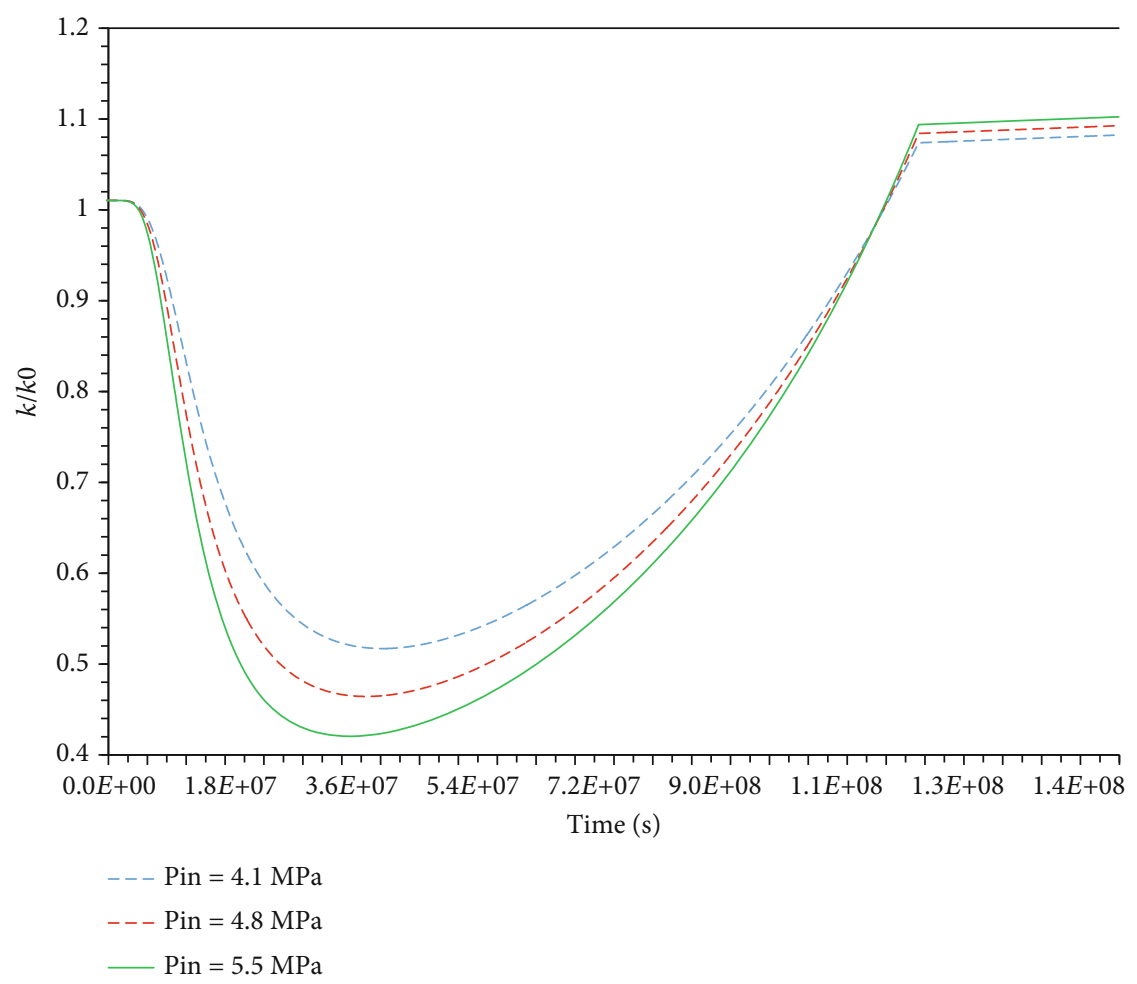

FIgURE 20: Evolution of permeability with different injection pressures of model II.

Figure 20 that the upper limit of permeability is at the final equilibrium state, which is proportional to the injection pressure, while the lower limit of permeability value is inversely proportional to the injection pressure. The permeability under different injection pressures after equilibrium has little difference. The main reason is that the free expansion deformation is limited by the roller constraints; so, the model cannot expand freely.

\section{Conclusions}

A nonequilibrium coal permeability model is developed to quantify the impact of local transient behaviors on gas flow triggered by gas injection. Based on the results of this study, the following conclusions can be drawn:

(1) The permeability of coal is restricted by the initial and ultimate pore-body strain ratio and the disturbance time. The equilibrium permeability is determined by the initial and the limit pore volume strain ratio, and the evolution time from the initial to the limit equilibrium permeability is determined by the interference time

(2) It is assumed in the literature that the current permeability data are measured under equilibrium conditions, but are distributed within the permeability range described by the equilibrium value. This suggests that the equilibrium hypothesis of those experiments may not be valid
(3) The coal permeability from the initial value to the final value all experienced a similar evolution stage. The injection pressure leads to an initial increase, and the fracture diffuses to the periphery, leading to a gradual decrease. The diffusion region expands from the fracture to the whole matrix region, leading to recovery, and finally reaches the equilibrium permeability

\section{Data Availability}

The data used to support the findings of this study are included within the article.

\section{Conflicts of Interest}

The author(s) declare(s) that they have no conflicts of interest.

\section{Acknowledgments}

This work was supported by the Fundamental Research Funds for the Central Universities (Grant No. 2020ZDPYMS02).

\section{References}

[1] J. D. N. Pone, M. Hile, P. M. Halleck, and J. P. Mathews, "Three-dimensional carbon dioxide-induced strain distribution within a confined bituminous coal," International Journal of Coal Geology, vol. 77, no. 1-2, pp. 103-108, 2009. 
[2] P. Au, J. Liu, and Y. Leong, "Yield stress and microstructure of washed oxide suspensions at the isoelectric point: experimental and model fractal structure," Rheologica Acta, vol. 55, no. 10 , pp. $847-856,2016$.

[3] C. Wang, J. Liu, J. Feng, M. Wei, C. Wang, and Y. Jiang, "Effects of gas diffusion from fractures to coal matrix on the evolution of coal strains: Experimental observations," International Journal of Coal Geology, vol. 162, pp. 74-84, 2016.

[4] S. Mazumder and K. H. Wolf, "Differential swelling and permeability change of coal in response to $\mathrm{CO} 2$ injection for ECBM," International Journal of Coal Geology, vol. 74, pp. 123-138, 2007.

[5] K. Li, S. Kong, P. Xia, and X. Wang, "Microstructural characterisation of organic matter pores in coal-measure shale," Advances in Geo-Energy Research, vol. 4, no. 4, pp. 372-391, 2020.

[6] R. Liu, B. Li, and Y. Jiang, "A fractal model based on a new governing equation of fluid flow in fractures for characterizing hydraulic properties of rock fracture networks," Computers and Geotechnics, vol. 75, pp. 57-68, 2016.

[7] X. Qin, Y. Zhou, and A. P. Sasmito, "An effective thermal conductivity model for fractal porous media with rough surfaces," Advances in Geo-Energy Research, vol. 3, no. 2, pp. 149-155, 2019.

[8] G. Liu, B. Yu, D. Ye, F. Gao, and J. Liu, "Study on evolution of fractal dimension for fractured coal seam under MULTIFIELD coupling," Fractals, vol. 28, no. 4, article 2050072, 2020.

[9] G. Liu, B. Yu, F. Gao, D. Ye, and F. Yue, "Analysis of permeability evolution characteristics based on dual fractal coupling model for coal seam," Fractals, vol. 28, no. 7, article 2050133, 2020.

[10] G. Liu, J. Liu, L. Liu, D. Ye, and F. Gao, "A fractal approach to fully-couple coal deformation and gas flow," Fuel, vol. 240, pp. 219-236, 2019.

[11] H. B. Zhang, J. Liu, and D. Elsworth, "How sorption-induced matrix deformation affects gas flow in coal seams: a new FE model," International Journal of Rock Mechanics and Mining Sciences, vol. 45, no. 8, pp. 1226-1236, 2008.

[12] J. Rutqvist and C. Tsang, "A study of caprock hydromechanical changes associated with $\mathrm{CO}_{2}$-injection into a brine formation," Environmental Geology, vol. 42, no. 2-3, pp. 296-305, 2002.

[13] Y. Wu, J. Liu, D. Elsworth, Z. Chen, L. Connell, and Z. Pan, "Dual poroelastic response of a coal seam to $\mathrm{CO}_{2}$ injection," International Journal of Greenhouse Gas Control, vol. 4, no. 4, pp. 668-678, 2010.

[14] W. Li, J. Liu, J. Zeng, Y. Leong, and D. Elsworth, "A fully coupled multidomain and multiphysics model for shale gas production," in 5th ISRM Young Scholars' Symposium on Rock Mechanics and International Symposium on Rock Engineering for Innovative Future, Okinawa, Japan, 2019.

[15] M. Lu and L. D. Connell, "A statistical representation of the matrix-fracture transfer function for porous media," Transport in Porous Media, vol. 86, no. 3, pp. 777-803, 2011.

[16] J. G. Wang, J. Liu, and A. Kabir, "Combined effects of directional compaction, non-Darcy flow and anisotropic swelling on coal seam gas extraction," International Journal of Coal Geology, vol. 109-110, pp. 1-14, 2013.

[17] Y. Peng, J. Liu, M. Wei, Z. Pan, and L. D. Connell, "Why coal permeability changes under free swellings: new insights,"
International Journal of Coal Geology, vol. 133, pp. 35-46, 2014.

[18] N. Joshi, C. S. P. Ojha, P. K. Sharma, and C. A. Madramootoo, "Application of nonequilibrium fracture matrix model in simulating reactive contaminant transport through fractured porous media," Water Resources Research, vol. 51, no. 1, pp. 390-408, 2015.

[19] R. Upadhyay and S. Laik, "A computational approach to determine average reservoir pressure in a coalbed methane (CBM) well flowing under dominant matrix shrinkage effect," Transport in Porous Media, vol. 116, no. 3, pp. 1167-1188, 2017.

[20] J. Li, W. Yu, D. Guerra, and K. Wu, "Modeling wettability alteration effect on well performance in Permian basin with complex fracture networks," Fuel, vol. 224, pp. 740-751, 2018.

[21] Y. Xue, T. Teng, F. Dang, Z. Ma, S. Wang, and H. Xue, "Productivity analysis of fractured wells in reservoir of hydrogen and carbon based on dual-porosity medium model," International Journal of Hydrogen Energy, vol. 45, no. 39, pp. 20240-20249, 2020.

[22] J. Zeng, J. Liu, W. Li, Y. K. Leong, D. Elsworth, and J. Guo, "Evolution of shale permeability under the influence of gas diffusion from the fracture wall into the matrix," Energy \& Fuels, vol. 34, no. 4, pp. 4393-4406, 2020.

[23] G. Liu, D. Ye, F. Gao, and J. Liu, “A Dual Fractal Poroelastic Model for Characterizing Fluid Flow in Fractured Coal Masses," Geofluids, vol. 2020, Article ID 2787903, 13 pages, 2020.

[24] J. Zeng, X. Wang, J. Guo, F. Zeng, and F. Zeng, "Modeling of heterogeneous reservoirs with damaged hydraulic fractures," Journal of Hydrology, vol. 574, pp. 774-793, 2019.

[25] W. Li, J. Liu, J. Zeng et al., "A fully coupled multidomain and multiphysics model for evaluation of shale gas extraction," Fuel, vol. 278, article 118214, 2020.

[26] Y. Peng, J. Liu, Z. Pan, L. D. Connell, Z. Chen, and H. Qu, "Impact of coal matrix strains on the evolution of permeability," Fuel, vol. 189, pp. 270-283, 2017.

[27] X. X. Liu, J. C. Sheng, J. S. Liu, and Y. Hu, "Evolution of coal permeability during gas injection-from initial to ultimate equilibrium," Energies, vol. 11, no. 10, p. 2800, 2018.

[28] J. Liu, X. Liang, Y. Xue, K. Yao, and Y. Fu, "Numerical evaluation on multiphase flow and heat transfer during thermal stimulation enhanced shale gas recovery," Applied Thermal Engineering, vol. 178, article 115554, 2020.

[29] J. Zeng, X. Wang, J. Guo, F. Zeng, and Q. Zhang, "Composite linear flow model for multi-fractured horizontal wells in tight sand reservoirs with the threshold pressure gradient," Journal of Petroleum Science and Engineering, vol. 165, pp. 890-912, 2018.

[30] H. Wang, R. Shi, D. Deng, Y. Jiang, G. Wang, and W. Gong, "Characteristic of stress evolution on fault surface and coal bursts mechanism during the extraction of longwall face in Yima mining area, China," Journal of Structural Geology, vol. 136, article 104071, 2020.

[31] H. Wang, S. Xue, R. Shi, Y. Jiang, W. Gong, and L. Mao, "Investigation of fault displacement evolution during extraction in longwall panel in an underground coal mine," Rock Mechanics and Rock Engineering, vol. 53, no. 4, pp. 18091826, 2020.

[32] M. Lu and D. L. Connell, "Swell of coal matrix induced by gas sorption and its partition to pore volume and bulk strains - a critical parameter for coal permeability," in 44th US rock 
mechanics symposium and 5th U.S.-Canada rock mechanics symposium, pp. 27-30, Salt Lake City, UT, 2010.

[33] L. Connell, Z. Pan, M. Lu, D. D. Heryanto, and M. Camilleri, "Coal permeability and its behaviour with gas desorption, pressure and stress," in SPE Asia Pacific Oil \& Gas Conference and Exhibition, pp. 18-20, Brisbane, Queensland, Australia, 2010.

[34] W. T. Patzek, D. B. Silin, S. M. Benson, and G. I. Barenblatt, "On vertical diffusion of gases in a horizontal reservoir," Transport in Porous Media, vol. 51, no. 2, article 5088959, pp. 141-156, 2003.

[35] J. Liu, J. Wang, Z. Chen, S. Wang, D. Elsworth, and Y. Jiang, "Impact of transition from local swelling to macro swelling on the evolution of coal permeability," International Journal of Coal Geology, vol. 88, no. 1, pp. 31-40, 2011.

[36] F. Zhou, T. Xia, X. Wang, Y. Zhang, Y. Sun, and J. Liu, "Recent developments in coal mine methane extraction and utilization in China: a review," Journal of Natural Gas Science and Engineering, vol. 31, pp. 437-458, 2016.

[37] M. Wei, J. Liu, X. Feng, C. Wang, and F. Zhou, "Evolution of shale apparent permeability from stress-controlled to displacement-controlled conditions," Journal of Natural Gas Science and Engineering, vol. 34, pp. 1453-1460, 2016.

[38] P. Cao, J. Liu, and Y. Leong, "Combined impact of flow regimes and effective stress on the evolution of shale apparent permeability," Journal of Unconventional Oil and Gas Resources, vol. 14, pp. 32-43, 2016.

[39] Z. X. Liu, Z. C. Feng, Q. M. Zhang, D. Zhao, and H. Guo, "Heat and deformation effects of coal during adsorption and desorption of carbon dioxide," Journal of Natural Gas Science and Engineering, vol. 25, pp. 242-252, 2015.

[40] X. Cui and R. M. Bustin, "Volumetric strain associated with methane desorption and its impact on coalbed gas production from deep coal seams," AAPG Bulletin, vol. 89, no. 9, pp. 11811202, 2005.

[41] M. S. A. Perera, P. G. Ranjith, and S. K. Choi, "Coal cleat permeability for gas movement under triaxial, non-zero lateral strain condition: a theoretical and experimental study," Fuel, vol. 109, pp. 389-399, 2013. 